Res Publica Revista de Historia de las Ideas Políticas

ISSN: $1131-558 \mathrm{X}$

\title{
A. Honneth, Reconocimiento. Una historia de las ideas europeas, Madrid, Akal, 2019,
} $203 \mathrm{pp}$.

Ya desde antes de ser nombrado director del prestigioso Instituto de Investigaciones Sociales de la Universidad de Frankfurt que dio nombre a la famosa escuela filosófica, Axel Honneth se había preocupado por el problema del reconocimiento. Un problema alrededor del cual giran muchas de las disputas de la filosofía política actual, como el debate entre Butler y Fraser entre reconocimiento y redistribución, o sea, entre la importancia y diferenciación entre lo "material" y lo "cultural", o las disputas sobre las llamadas "políticas identitarias". En sus artículos recogidos en el volumen La sociedad del desprecio (publicado por Trotta en 2011), Honneth ya había sentado las bases para una teoría del reconocimiento que distinguiera entre la visibilidad social y la visibilidad óptica, algo que profundizó en su agudo debate con Nancy Fraser (2010) pero que también aparece en su agudo ensayo breve sobre el concepto de reificación (2008) o en Patologías de la razón (2009). En 2018 se propuso hacer una "historia de las ideas europeas" únicamente a partir del concepto de reconocimiento cuyo resultado es el libro dedicado a Habermas que Sandra Chaparro tradujo para la editorial Akal -colección Pensamiento crítico- en 2019.

El impulso historiográfico al que obedece Honneth no es universalizador ni totalizante, al contrario: el libro se divide en tres grandes capítulos dedicado a las tres potencias intelectuales más importantes de Europa: Francia, Reino Unido y Alemania y un último capítulo en el que se establece el estudio comparativo. Se trata ya no solo, como en sus anteriores escritores, de mostrar la actualidad del concepto de reconocimiento, sino de buscar su origen en cada uno de estos países para mostrar su importancia implícita en el desarrollo de la filosofía europea. Así, frente a la idea de que el concepto de reconocimiento nace en la teoría política de Thomas Hobbes, Honneth rastrea el origen en el moralismo francés, concretamente en la filosofía de Jean-Jacques Rousseau. En efecto, fue el autor ilustrado quien recogió el término amour propre, utilizado por el duque de La Rochefoucauld para referirse a la pasión natural de los seres humanos por hacerse notar en público, la necesidad de hacerse pasar, a ojos de los demás, por excelente. Para Rousseau, este amour propre no es sino "la necesidad, fruto de un proceso histórico, de aparentar mayor valía y rango que los demás" (p. 36). Honneth observa que este concepto moralista tiene mucho que ver con el de reconocimiento, pues no es otra cosa que el afán de ser reconocido, la necesidad de notoriedad. Y el dominio del amour propre, para Rousseau, significaba la conversión de nuestra vida en una "segunda naturaleza", una manera de fingir nuestra personalidad que acababa produciendo una pérdida de sí. Así pues, la reflexión retrospectiva que traza Honneth lo lleva a concluir que en toda la filosofía francesa, desde Rousseau hasta Althusser pasando por Sartre, el reconocimiento tiene un cariz negativo. El caso del filósofo existencialista es claro: el reconocimiento del Otro convierte al ser-para-sí en ser-en-sí, lo que conlleva "el drama del sujeto que se experimenta a sí mismo como un ser libre en un mundo lleno de posibilidades (...) que solo puede percibir al Otro como un ser indeterminado, libre y abierto al futuro si ambos se contemplan recíproca y simultáneamente como meros objetos" (p. 60).

Si en el ámbito francés el reconocimiento tiene el carácter de perdida de sí, en el anglosajón, articulado a través del concepto de sympathy, el reconocimiento tiene una carga altamente positiva. Sympathy es, para David Hume, aquella disposición especial del ser humano para ponerse en el lugar del otro, como dos cuerdas que se contagian la vibración. Así, el filósofo escocés pretendía explicar la relación entre la sensación de gusto o disgusto y los juicios morales. Hume, explica Honneth, da el primer paso, pero no se puede decir que su sympathy o empatía implique reconocimiento: "no podemos hablar de reconocimiento cuando sólo percibimos al Otro como un sujeto cuyas experiencias emocionales podemos revivir fácilmente (...) para poder hablar de reconocimiento entre seres humanos aún debemos experimentar una dependencia normativa del Otro" (p. 80). Sin embargo, en la idea humeana de que es necesario siempre un observador externo e imparcial a la hora de dilucidar un juicio individual, sí podemos encontrar el origen del reconocimiento anglosajón. Para Hume, someterse al juicio de un observador es beneficioso, mientras que para Rousseau aquello conllevaba la desarticulación del yo. Pero son, a ojos de Honneth, Adam Smith y Stuart Mill quienes cincelan coherentemente la idea de reconocimiento en el XVIII inglés. El primero investigó cómo nuestra conducta moral depende de formas plenas de reconocimiento social, tratando el observador externo de Hume como una voz del interior de la conciencia; el segundo prescinde del observador imparcial o juez interior, pero afirma en El utilitarismo que "la dependencia de las personas del juicio de los demás implica la necesidad de comprobar que nuestra conducta responde a las expectativas normativas de la co- 
munidad, real o idealizada, compuesta por todos nuestros contemporáneos" (p. 108). Pese a que ninguno de los tres autores que analiza Honneth utiliza el término "reconocimiento", el estudio de sus teorías políticas demuestra que ambos tienen muy en cuenta la intersubjetividad y que le dan una apreciación positiva.

Si bien los dos primeros capítulos pueden parecer un poco apresurados, Honneth se muestra mucho más lúcido cuando pasa a analizar la tradición de la que es partícipe. La categoría dieciochesca que Honneth analiza es la de respeto (Achtung), pues para el Kant de la Fundamentación de la metafísica de las costumbres, "lo que nos hace renunciar a nuestras intenciones egocéntricas es la percepción, con ayuda de los sentidos, de que todo ser humano encarna ejemplarmente un valor que merece nuestro respeto" (p. 126). En su lectura de Kant, Honneth se arriesga a decir que el concepto de respeto es el que sirve de puente entre la naturaleza y el espíritu, ya que "el respeto hacia los demás altera la naturaleza de nuestras necesidades, porque nos obliga a dar prioridad a los mandatos morales de la razón sobre nuestros intereses egocéntricos" (p. 127). Sin embargo, la percepción kantiana del respeto era ambivalente y contradictoria, pues "por un lado, supuestamente toda persona debería experimentar respeto de forma espontánea en el mismo momento en el que se encuentra con otro sujeto; por otro, el sistema sólo parece funcionar cuando nos representamos a nuestro contener como un ser moral porque le reconocemos una capacidad de juicio especial" ( $p$. 131). Kant introdujo en la filosofía alemana la disputa, pero fue Fichte en su obra de 1796 Fundamentos del derecho natural según los principios de la doctrina de la ciencia quien elaboró "el documento constitutivo de una idea de reconocimiento específicamente alemana" (p. 134). El concepto de exhortación de Fichte, mediante el cual pretende explicar la toma gradual de conciencia de sí mismo que tiene un sujeto, necesita necesariamente de la presencia de Otro que sale a nuestro encuentro. Lo importante de la reflexión de Fichte es que ambos sujetos, en la comunicación de la que nace la exhortación, han de dar por hecho, para que esta se produzca, cada uno la racionalidad y la capacidad de reaccionar libremente del Otro. Fichte añade: "ninguno de los dos puede reconocer al otro si no se reconocen mutuamente; ninguno puede tratar al otro como un ser libre si ese trato no es recíproco" (p. 138), inaugurando así en el contexto terminológico germánico la idea de reconocimiento.

Sin embargo, dos teóricas contemporáneas del reconocimiento como Fraser y Butler coinciden en interceptar los orígenes del reconocimiento en la filosofía de Hegel. Hegel dio respuesta, según Honneth, a la problemática de por qué, en el encuentro mutuo entre dos sujetos que cataliza el reconocimiento, surge la libertad del Otro. El joven Hegel creía que el amor -ese vínculo del vínculo y del no-vínculo- era lo que posibilitaba "estar consigo mismo en el Otro". Siguiendo los principios de la dinámica amorosa, reconocer supone "autolimitar los propios intereses y así dotar al amado, explícitamente, de la libertad que precisa para determinar sus intereses y necesidades sin coacción alguna" (p. 146), por lo que el reconocimiento conduce a libertad individual si cumple las condiciones de ser mutuo, suponer una autolimitación complementaria y estar al alcance de la percepción de todos. Así, podemos ver cómo en Hegel ya hay un salto importante en la categoría de reconocimiento, que ha pasado a ser un concepto normativo que se incluye en el ámbito de la comunicación humana y explica la configuración de la intersubjetividad.

El viejo Hegel abandonó su idea del amor y elaboró una teoría del reconocimiento según la cual este estaba mediado siempre por la institución; en la dialéctica del amo y el esclavo el reconocimiento mutuo es la condición necesaria de una conciencia de libertad objetiva. Kojève interpretó, en sus famosos comentarios a la $\mathrm{Fe}$ nomenología del espíritu, que en anhelo del que se habla en ese famoso pasaje es siempre un "anhelo del Otro", es decir: necesidad de reconocimiento. Esta "necesidad" de reconocimiento constituye el "deseo de realizar plena y libremente nuestra capacidad innata de autodeterminación racional" (p. 152). Por lo tanto, para Hegel la intersubjetividad no era dependiente del marco institucionalmente reglado. Así pues, el respeto en las formas de actuación entre sujetos que se reconocen es algo que está convenido, por lo que todo encuentro intersubjetivo se caracteriza por la expectativa de la recíproca igualdad.

En el último capítulo, Honneth realiza un encomiable trabajo de síntesis histórica y funde todas las versiones del reconocimiento previamente presentadas en un estudio comparativo. Así, se recuerda que, mientras que en caso francés el reconocimiento es básicamente lo que ahora entendemos como reconocimiento social, en el caso alemán el reconocimiento se plantea desde la lucha por la autodeterminación individual en el marco de la comunidad social, "de manera que (...) el reconocimiento es un acto diádico de autolimitación moral, que deben llevar a cabo al menos dos sujetos recíprocamente para demostrarse el uno al otro su racionalidad y confirmar su pertenencia a una comunidad de seres racionales" (p. 161). Honneth pretende así, tras haber presentado las diferencias y similitudes entre las doctrinas en los capítulos anteriores, elaborar un marco para la integración de los tres modelos presentados. Para ello, elige el modelo alemán, pues considera que es el más adecuado para integrar los otros al ser el que mejor se adhiere a la idea de que la praxis social nos vincula a las normas sociales por medio del reconocimiento mutuo de un derecho de los sujetos a validarlas e interpretarlas. De Hegel pasa a Althusser, pensador que le sirve para introducir una visión del reconocimiento más contemporánea, intrínsecamente ligada a la política.

En realidad, no se trata, como señala el título, de una "Historia de las ideas europeas", sino de una revisión histórica del concepto de reconocimiento, que muestra su equivocidad dependiente de las distintas tradiciones filosóficas europeas. El planteamiento de esta novedosa genealogía sirve de apoyo para otros trabajos anteriores de Honneth, tales como La sociedad del desprecio (2011) o Reification (2008), y constituye otro paso más para la formación de una sólida, contemporánea y comprometida teoría del reconocimiento. 